\title{
Caudal Regression Syndrome: A Journey from Sweet to Sour: A Unique Complication of Maternal Diabetes Mellitus: A Case Report of a Still Born Fetus
}

\author{
Dodampahala S. H. ${ }^{1}$, Dodampahala S. K. ${ }^{2}$, Rahubaddha A. N. ${ }^{3}$ \\ ${ }^{1}$ Associate Professor, Department of Obstetrics and Gynecology, Faculty of Medicine, University of Colombo, Sri Lanka \\ ${ }^{2}$ Undergraduate Research Student \\ ${ }^{3}$ Research Associate, Department of Obstetrics and Gynecology, Faculty of Medicine, University of Colombo, Sri Lanka
}

\begin{abstract}
Caudal regression syndrome is a rare congenital disorder that encompasses a spectrum of anomalies. A case of caudal regression syndrome and polyhydraminios that was associated with uncontrolled pre-gestational diabetes mellitus is presented. The outcome was a still born fetus delivered at the gestational age of 22 weeks.
\end{abstract}

Keywords: sacral agenesis, caudal regression syndrome, maternal Diabetes mellitus, fetal abnormality

\section{Introduction}

Caudal regression syndrome and caudal dysgenesis syndrome are broad terms that refer to a heterogenous group of severe congenital anomalies affecting the caudal spine and spinal cord, the lower limbs, the hindgut and the urogenital system. The exact etiology is poorly understood, but maternal diabetes, genetic predisposition, and vascular hypoperfusion have been proposed (1). About 15-25\% of children with caudal regression syndrome are born to mothers with insulin dependent diabetes mellitus. The risk of caudal dysplasia is up to 600 times higher in these infants (2).Itis considered as the most characteristic of all congenital anomalies associated with maternal diabetes mellitusby some authorities (3). Here we present a case of a still born fetus with caudal regression syndrome, delivered pre term by a mother with pre gestational diabetes mellitus.

\section{Case Report}

Mrs A, a 36 year old resident of Maldives presented to us in her second pregnancy. She is a diagnosed patient with pre gestational diabetes mellitus. Her first pregnancy was also complicated with pre gestational diabetes mellitus leading to the birth of a single live female fetus weighing $3.98 \mathrm{~kg}$ by a caesarian section. Since the time of the first pregnancy she had been on treatment with insulin. However she had defaulted treatment in the pre-conceptional period of the index pregnancy. She conceived at a time when her HbA1c was $8.9 \mathrm{~g} / \mathrm{dl}$ and random blood sugar was $233 \mathrm{mg} / \mathrm{dl}$. After detection of the pregnancy, she was started on 20 units of pre-mixed insulin bd. The anomaly scan, done at 16 weeks of gestation, did not show the fetal spine properly. She visited Sri Lanka to obtain the opinion from a specialist in fetal medicine and for further evaluation. At the time we reviewed the patient, her $\mathrm{Hb}$ was $11.3 \mathrm{~g} / \mathrm{dl}$ and CRP was of normal value. Her blood group was $B$ negative and she was not sensitized. HbA1cwas $8.8 \mathrm{~g} / \mathrm{dl}$ and RBS was $198 \mathrm{mg} / \mathrm{dl}$. Post prandial blood sugar was $168 \mathrm{mg} / \mathrm{dl}$. A 3D ultra sound scan of the fetus revealed a gross deficiency in the formation of lower sacral spine which was confirmed by a subsequent fetal MRI. There was also evidence of increased liquorwith the AFI being 16.5, well above the mean value for that particular gestational age.Increased AFI has led Mrs. Ato trigger pre-term labour at 22 weeks of gestation. Labour was facilitated as there was a gross fetal malformation. She delivered a stillborn male fetus weighing $636 \mathrm{~g}$. There were malformed lower limbs with popliteal webbing and external evidence of sacral agenesis.

Subsequent postmortem revealed a narrow pelvis and short deformed lower limbs therefore confirming our diagnosis. The post mortem report further revealed malrotation of bowel. Placenta was small and irregular, weighing 131g with the presence of small inter villous thrombi.

She was discharged after a detailed counselling with regard to next pregnancy, timing and the proper control of diabetes prior to conception. It was emphasized that HbA1c to should be kept below 6 as future reference level at conception. Since the patient is over 36 years, she was also advised to take pre-conceptional folic acid, nuchal translucency screening at $11-13$ weeks, triple assay in addition to the diabetes control. She was also advised to have a 3D skeletal survey in 14-16 weeks to rule out a recurrence. 


\section{International Journal of Science and Research (IJSR) \\ ISSN (Online): 2319-7064}

Index Copernicus Value (2013): 6.14 | Impact Factor (2015): 6.391

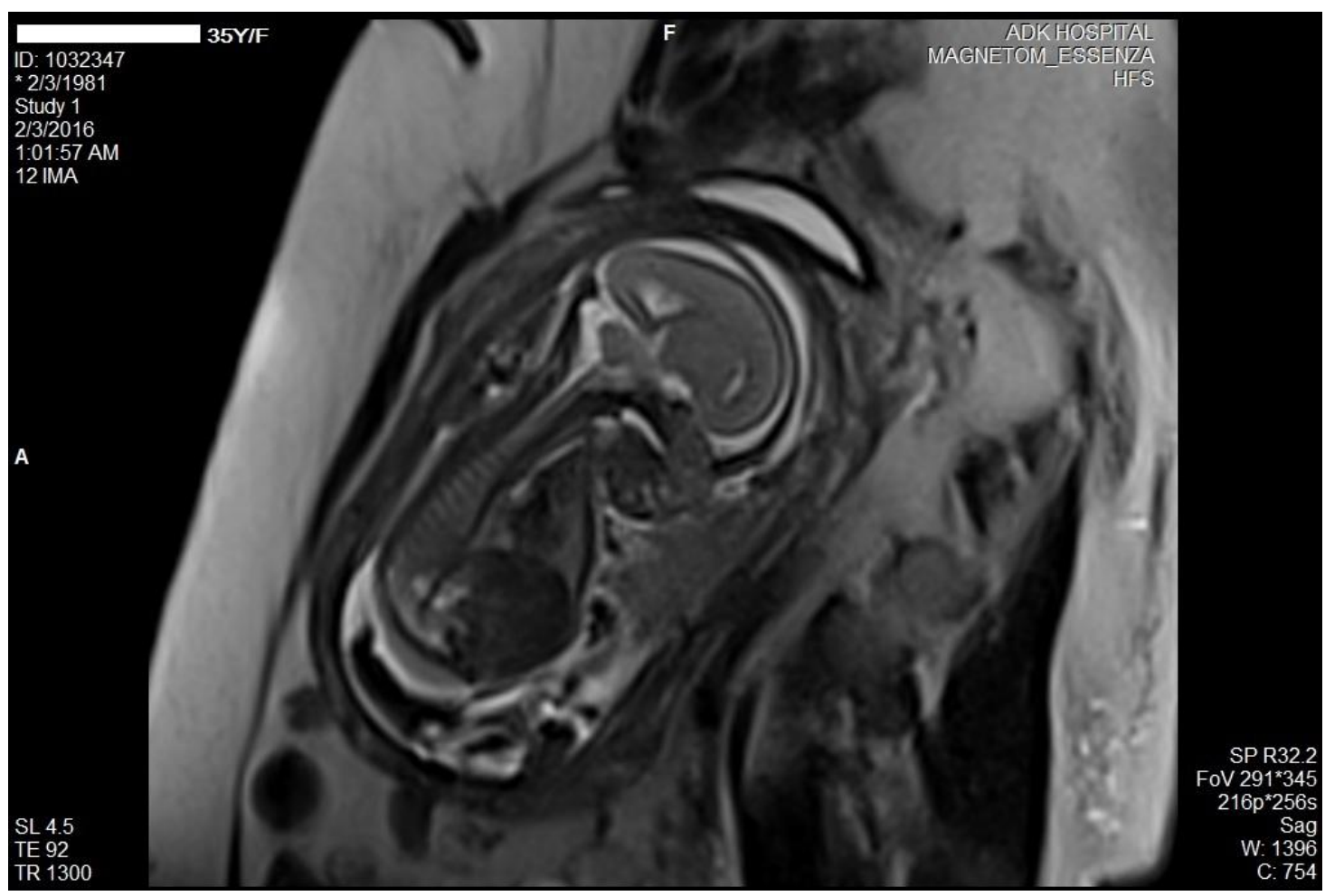

Figure 1: MRI scan of the fetus showing lower spinal digenesis

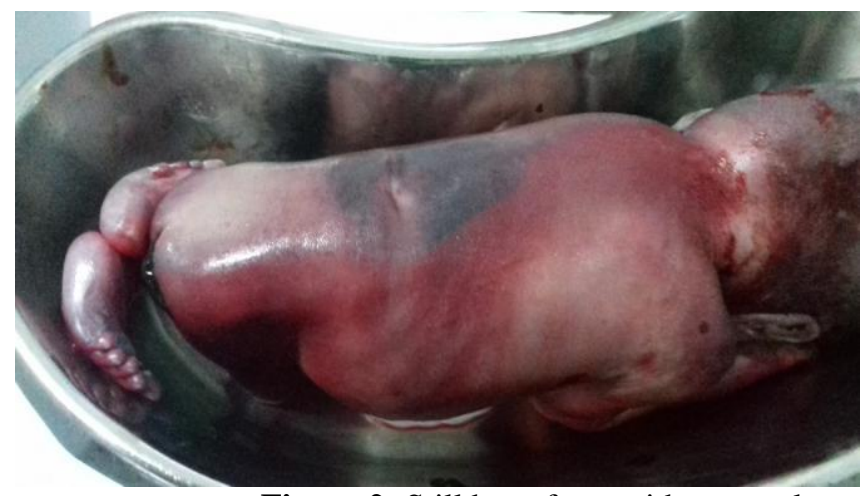

Figure 2: Still born fetus with external evidence of sacral and lower limb malformation

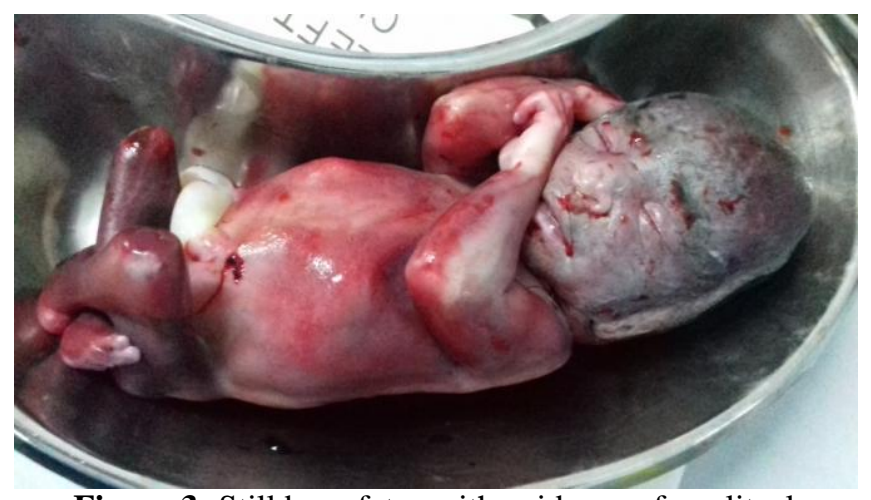

Figure 3: Still born fetus with evidence of popliteal webbing and fixed flexion deformity

\section{Discussion}

Caudal regression syndrome represents a spectrum of rare congenital defects of the caudal region. It is a rare disorder with an estimated incidence of 1:7,500 - 1:100,000, with a male to female ratio of 2.7:1(5),(6). This spectrum encompasses abnormalities ranging from absence of a few terminal coccygeal segments to lumbosacral agenesis and more extensive forms such as sirenomelia. In our case there were sacral agenesis, popliteal webbing and short hind limbs. Associations reported frequently with caudal regression syndrome include genitourinary, anorectal, vertebral, and cardiopulmonary anomalies and may also include VACTERL syndrome. It is regarded as a consequence of abnormal development of the structures derived from the caudal mesoderm of the embryo before the fourth week of gestation (6). Approximately $15 \%$ to $20 \%$ of the fetuses affected by caudal regression syndromehave diabeticmothers. Only $1 \%$ of children of diabetic mothers are affected by this disorder. However, because it has been found that only $16 \%$ to $22 \%$ of the mothers of these patients have diabetes, it is clear that the syndrome is not specific to diabetes, although it is one of the best known associations with caudal regression syndrome (2), (7).

Maternal diabetes mellitus, due to fetal polyuria, isassociated with polyhydramnios which in return is associated with pre-term labour which could have been the closest reason in our case that led to the delivery of a still born fetus at the gestational age of 22 weeks (8). This case report in particular bear evidence to the devastating complications, uncontrolled pre-gestational diabetes can impose on a developing fetus and the overall outcome of a pregnancy. We reiterate the importance of pre-pregnancy counselling and optimization of maternal diabetes before conceiving to prevent such unfortunate circumstances.

\section{Conclusion}

Uncontrolled pre-gestational diabetes mellitus can rarely cause, apart from other congenital malformations, caudal regression syndrome. It could also result in polyhydramnios due to increased production of urine in the fetus. These two 
complications were evident in our case which resulted in a still born fetus with caudal regression syndrome at the gestational age of 22 weeks. Hence it is of paramount importance that women with diabetes mellitus reach optimum glycemic control before getting pregnant.

\section{References}

[1] Lynch SA, Wang Y, Strachan T, Burn J, Lindsay S. Autosomal dominant sacral agenesis: Currarino syndrome. J Med Genet. 2000;37:561-566. doi: 10.1136/jmg.37.8.561

[2] Welch JP, Aterman K (1984) Syndrome of caudal regression: a review, including etiologic considerations and evidence of heterogeneity. Pediatr Path 2:313-327

[3] DeBoer T, Wewerka S, Bauer PJ, Georgieff MK, Nelson CA. Explicit memory performance in infants of diabetic mothers at 1 year of age. Dev Med Child Neurol. 2005 Aug. 47(8):525-31

[4] Sonek JD1, Gabbe SG, Landon MB, Stempel LE, Foley MR, Shubert-Moell K. Antenatal diagnosis of sacral agenesis syndrome in a pregnancy complicated by diabetes mellitus. Am J Obstet Gynecol. 1990 Mar;162(3):806-8.

[5] Unsinn KM, Geley T, Freund MC et-al. US of the spinal cord in newborns: spectrum of normal findings, variants, congenital anomalies, and acquired diseases. Radiographics. 20 (4): 923-38.

[6] Singh SK, Singh RD, Sharma A. Caudal regression syndrome - case report and review of literature. PediatrSurg Int. 2005;21(7):578-581.

[7] Shah JR, Sainani N, Patkar DP. Caudal regression syndrome with sacral rib: MRI features. ActaRadiol. 2006;47(8):862-864.

[8] Influence of polyhydramnios on perinatal outcome in pregestational diabetic pregnancies. Idris N, Wong SF, Thomae M, Gardener G, McIntyre DH. Ultrasound ObstetGynecol [2010] 